\title{
Dermatology + Psychosomatics - the First Three Years
}

The third year of Dermatology + Psychosomatics closes with the present issue. The editors' vision to create an international organ for research in psychosomatic dermatology apparently becomes more and more realized. In this issue, authors from all over the world present their clinical and scientific perspective regarding various dermatological diseases, this time especially focusing on dysmorphic disorders and artefactitious dermatitis.

Radmanesh et al. [2002] from Iran present interesting results concerning patients preoccupied with losing their hair. They underline the dysmorphic disorder in these patients with normal hair status and state a high prevalence of affective disorders in their sample. The special relevance of hair for Iranian people is described as well. By emphasizing the necessity to combine different therapeutic approaches and to integrate psychotherapy into the treatment, the authors agree with Chuang et al. [2002] from Taiwan: Hair loss as an adverse side effect of antiepileptic therapy may be treated by taking into account its psychosocial strains.

The educational article by Höring and Gieler [2002] completes this issue. The authors describe alopecia areata with special attention to psychosomatic aspects, and they recommend the use of psychometric instruments to detect affective disorders. Two articles, one from the United States and one from Greece, deal with artifactitious dermatological diseases. The case report by Silvan and Silverberg [2002] describes self-mutilation in a patient with borderline personality disorder. Leonardou et al. [2002] present a case of severe dermatitis artefacta in a patient with unusual skin conditions. Both articles show in a very vivid way how severe psychological disorders can be converted into dermatological symptoms. Dermatologists and psychiatrists should cooperate particularly closely in the treatment of such dermatoses.

The editors are convinced to present in this issue of DeRMATOLOGY + PSYCHOSOMATICS another collection of articles of high clinical and scientific impact.

I. Zschocke, Freiburg i. Br.

\section{References}

Chuang Y-C, Chang W-N, Chen I-L, Yang J-Y, Hoc J-C, Kuo H-W: Topiramate-induced hair loss: Case report. Dermatol Psychosom 2002;3:183-184.

Höring C-M, Gieler U: Alopecia areata. Dermatol Psychosom 2002;3:196-197.

Leonardou A, Stefanis N, Vaslamatzis G, Trikkas G, Papadimitriou G, Christodoulou G: Dermatitis artefacta in a woman with Munchausen syndrome. Dermatol Psychosom 2002;3:190-192.

Radmanesh M, Shafiei S, Mortazavi ME: Hair loss dysmorphic disorder - a frequently encountered and often neglected disorder. Dermatol Psychosom 2002:3:193-195.

Silvan M, Silverberg N: Self-Mutilation with suicidal intent: An example of the integrated treatment approach to psychocutaneous illness. Dermatol Psychosom 2002;3:185-189.

\section{KARGER @ 2002 S. Karger GmbH, Freiburg

